\title{
Resistência de cultivares de milho convencional a lagarta do cartucho
}

\author{
Resistance of maize conventional cultivars to the fall armyworm
}

\section{Renato Franco Oliveira de Moraes, Wellington Ivo Eduardo, Aildson Pereira Duarte, Arlindo Leal Boiça Júnior}

\begin{abstract}
Universidade Estadual Paulista "Júlio de Mesquita Filho" (UNESP), Faculdade de Ciências Agrárias e Veterinárias (FCAV), Departamento de Fitossanidade. Via de Acesso Prof.Paulo Donato Castellane s/n 14884-900 - Jaboticabal, SP, renatomoraes2@hotmail.com
\end{abstract}

\section{$\begin{array}{ll}\text { Recebido em: 10/06/2016 Aceito em:22/05/2017 } & \text { Acto }\end{array}$}

\begin{abstract}
Resumo: A lagarta do cartucho é uma das principais pragas do milho, sendo controladas principalmente por inseticidas químicos, porém esta tática de manejo pode ocasionar riscos ao meio ambiente e à saúde humana. A utilização de cultivares resistentes pode diminuir a população da praga, ocasionando menos danos às lavouras. Sendo assim, este trabalho teve como objetivo identificar cultivares de milho com características de resistência à lagarta Spodoptera frugiperda. Foram utilizados 11 cultivares de milho não transgênico em testes de preferência alimentar com e sem chance de escolha, e teste de antibiose. Empregou-se o delineamento experimental inteiramente casualizado para o teste sem chance, e blocos casualizados para o teste com chance de escolha, ambos com seis repetições, e o delineamento inteiramente casualizado com 30 repetições para o teste de antibiose. Nos testes de preferência, avaliou-se a atratividade aos 1, 3, 5, 10, 15, 30, 60, 120, 360, 720 e 1440 minutos e a porcentagem de injúria. No teste de antibiose avaliou-se os aspectos biológicos de 30 lagartas por tratamento. A cultivar AS 1581 apresentou características de resistência na categoria não preferência para alimentação. As cultivares TRUCK e IAC 8390 apresentaram características de resistência na categoria antibiose a $S$. frugiperda.
\end{abstract}

Palavras-chave: antibiose, não preferência, resistência de plantas a insetos, Spodoptera frugiperda, Zea mays $L$.

\begin{abstract}
Fall armyworm is a major corn pest and is mainly controlled by chemical insecticides but is management tactic can cause risks to the environment and human health. The use of resistant cultivars may reduce the pest population causing less damage to crops. Therefore this study aimed to evaluate the resistance of maize conventional cultivars to Spodoptera frugiperda. Eleven non transgenic maize cultivars were used in free-choice and non-choice tests, and for antibiosis assay. We used a completely randomized blocks design was used for the non-choice test and randomized blocks design for the free-choice test, both with six replicates, and completely randomized blocks design for the antibiosis assay, with 30 replicates. In the preference tests, the attractiveness was evaluated at 1, 3, 5, 10, 15, 30, 60, 120, 360, 720 and 1440 minutes after the release of the insects and the percentage of injury caused by the larvae after the end of the attractiveness. In antibiosis test, 30 newly hatched larvae were individualized into Petri dishes containing corn leaves, which were replaced as necessary until the end of the larval cycle. The cultivar AS 1581 is resistant characteristics of category no preference for feeding. The cultivars TRUCK and IAC 8390 have resistance characteristics in category antibiosis to $S$. frugiperda.
\end{abstract}

Keywords: antibiosis, non-preference, plant resistance to insects, Spodoptera frugiperda, Zea mays L.

\section{Introdução}

O milho é um dos cereais mais cultivados no Brasil, com área plantada de 17 milhões de hectares e produção de mais de 91 milhões de toneladas na safra 2016/17 (Conab, 2017). Durante seu cultivo, o milho é hospedeiro 


\section{Revista Agrarian}

ISSN: 1984-2538

de várias espécies de insetos fitófagos, que podem ocorrer em diferentes momentos do ciclo fenológico da planta, dentre estes, a lagarta-docartucho, Spodoptera frugiperda (J.E. Smith, 1797) (Lepidoptera: Noctuidae) é considerada a mais importante praga do milho no Brasil (Cruz et al., 2011). Em condições favoráveis aumenta sua população rapidamente podendo destruir as folhas, o cartucho do milho, causar danos nas espigas e reduzir a produção final de grãos (Campos \& Boiça Júnior, 2012).

Para o controle de $S$. frugiperda a utilização de defensivos agrícolas de forma frequente e intensa é o método mais utilizado (Correia et al., 2009). No entanto, com o lançamento das plantas de milho geneticamente modificadas contendo Bacillus thuringiensis berliner 1915, este tipo de planta passou a ser utilizada em quase totalidade das lavouras visando ao manejo de insetos pragas. Segundo o levantamento realizado, a área de milho transgênico no Brasil atingiu $88,4 \%$ da área total cultivada com milho na safra de 2016/17 (Céleres, 2017).

Segundo Zancanaro et al. (2012) quando as plantas transgênicas são utilizadas em grandes áreas, sem a realização do manejo adequado, alguns insetos-alvo da tecnologia $\mathrm{Bt}$ podem desenvolver resistência, inviabilizando assim a utilização destes cultivares. Devido à alta pressão de seleção gerado pelo plantio em extensas áreas e o manejo inadequado das culturas transgênicas, o problema como resistência dos insetos tem tornando-se frequentes na agricultura brasileira (Farias et al., 2014; Sorgatto et al., 2015).

Como alternativa ao uso de plantas transgênicas, tem-se o emprego de cultivares convencionais resistentes, assim essas plantas com características de resistência podem ser utilizadas em substituição as plantas transgênicas, na adoção do refúgio, ou ser utilizadas como fonte de resistência em programas de melhoramentos (Nogueira, 2015).

Por definição, plantas resistentes são aquelas que devido à soma de seus genes constitutivos, expressam características fenotípicas físicas, morfológicas e ou químicas, que as fazem ser menos infestadas ou injuriadas do que outras em igualdade de condições, proporcionando redução na população de pragas, efeito cumulativo, compatibilidade com outras táticas de controle, podendo ser utilizada em programas de manejo integrado de pragas sem onerar o custo agricultor (Boiça Júnior et al., 2014),

Desse modo, pesquisas na linha de resistência de plantas à lagarta-do-cartucho que buscam identificar fontes de resistência têm sido realizadas. Boiça Júnior et al. (2001) e Ota et al. (2011) identificaram cultivares que sofreram menor ataque da lagarta-do-catucho. Viana \& Ponteza (2000), também estudaram a resistência de genótipos de milho a $S$. frugiperda, e constataram que, o genótipo CMS 14C apresentou resistência na categoria antibiose. CMS 24 e CMS 23 apresentaram também esse mecanismo, porém em menor intensidade, destacando ainda que Zapalote Chico e BR 201 apresentaram não preferência para alimentação, e CMS $14 \mathrm{C}$ e Zapalote Chico não preferência para oviposição. Assim, o presente trabalho teve por objetivo identificar cultivares de milho com características de resistência à lagarta $S$. frugiperda.

\section{Material e Métodos}

Os ensaios foram realizados no período de outubro de 2013 a fevereiro de 2014, no Laboratório de Resistência de Plantas a Insetos, do Departamento de Fitossanidade da Faculdade de Ciências Agrárias e Veterinárias FCAV/UNESP, sob condições de temperatura de $25 \pm 1^{\circ} \mathrm{C}$, umidade relativa de $70 \pm 10 \%$ e fotofase de 12 horas.

Para a realização dos testes, as cultivares foram semeadas em vasos de 5 litros, contendo uma mistura de terra, esterco e areia na proporção de 3:1:1, respectivamente, onde estes foram mantidos em casa de vegetação e irrigadas periodicamente. As lagartas utilizadas foram provenientes de uma criação própria mantida em dieta artificial de Greene et al. (1976).

Foram realizados testes de não preferência para alimentação, com e sem chance de escolha, e antibiose, com as 11 cultivares de milho não transgênicas: AG 7088, BX 1293, AG 5055, IAC 8390, AS 1581, TRUCK, AS 1596, SHS 7780, DKB 370, 20A78 e 2B587, adotando o delineamento inteiramente casualizado com $10 \mathrm{e}$ 30 repetições, respectivamente. 


\section{Revista Agrarian}

ISSN: 1984-2538

No teste com chance de escolha, discos foliares de sete $\mathrm{cm}^{2}$ das cultivares milho, foram distribuídos equidistantes do centro em arenas de vidro (23 $\mathrm{cm}$ de diâmetro por dois $\mathrm{cm}$ de altura). E para o teste sem chance de escolha, os discos foliares foram colocados individualmente em placas de Petri (nove $\mathrm{cm}$ de diâmetro por um $\mathrm{cm}$ de altura). Ambas as arenas foram forradas com papel filtro levemente umedecido com água deionizada, onde foi liberada uma lagarta de $S$. frugiperda de $3^{\circ}$ instar por cultivar. A utilização de lagartas de $3^{\circ}$ instar foi definida devido ao hábito canibal desta espécie em ínstares mais avançados (Luginbill, 1928).

Foram realizadas avaliações de atratividade em ambos os testes com 1, 3, 5, 10, 15,30 , minutos e 1, 2, 6 e 12 horas após a liberação das lagartas. Ao término da atratividade foi estimada a porcentagem de injúria ocasionada pela alimentação das lagartas que variou de 0 a $100 \% \quad(0 \%$ sem injúrias e $100 \%$ totalmente injuriadas) atribuídas por dois avaliadores.

Para o teste de antibiose, 30 lagartas recém-eclodidas foram individualizadas e acondicionadas em placas de Petri (nove $\mathrm{cm}$ de diâmetro por um $\mathrm{cm}$ de altura), forradas com papel filtro levemente umedecido com água deionizada, contendo folhas das respectivas cultivares, sendo que cada lagarta representou uma repetição. Diariamente, as folhas foram trocadas e os excrementos eliminados a fim de evitar possível contaminações, e consequentemente a redução na qualidade do alimento. Este procedimento foi realizado até as lagartas se trasnformarem em pupas, que foram pesadas em balança eletrônica de precisão com 24 horas de idade, separadas por sexo, e acomodadas novamente em placas de Petri forrada com papel filtro até a emergência dos adultos.

Para cada cultivar, à medida que ocorria a emergência dos casais de mesmo dia, estes eram individualizados em gaiolas cilíndricas de PVC (12 cm de diâmetro e $10 \mathrm{~cm}$ de altura), protegidas na parte superior com tecido tipo "voile" $\mathrm{e}$ forradas em seu interior com papel sulfite branco. Nas gaiolas, os adultos foram alimentados com solução de mel a $10 \%$, fornecida por meio de um chumaço de algodão embebido. $\mathrm{O}$ mesmo procedimento foi adotado para os adultos remanescentes e não acasalados. Diariamente, as posturas foram recolhidas, identificadas e colocadas em tubos de vidro (dois $\mathrm{cm}$ de diâmetro por cinco $\mathrm{cm}$ de profundidade). Para realizar a contagem dos ovos, estes foram limpos cuidadosamente com auxílio de um pincel fino para eliminar o excesso de escamas, possibilitando assim, a estimação do número de ovos em um microscópio estereoscópico seguindo metodologia proposta por Beserra \& Parra (2005).

Os parâmetros biológicos avaliados no teste de antibiose foram: duração e viabilidade do período larval; peso larval aos 10 dias; duração e viabilidade da fase pupal; peso de pupa com $24 \mathrm{~h}$ de idade; razão sexual; longevidade dos adultos; número total de ovos, número de postura, e ciclo de vida (período a eclosão da lagarta a morte do adulto).

Para análise estatística dos dados da atratividade foram calculadas as médias dos períodos de 1 a 30 minutos e 1 a 12 horas. No teste de antibiose as 30 (repetições) foram agrupadas em cinco grupos e calculadas a média das seis lagartas para cada parâmetro avaliado. $\mathrm{O}$ número de repetições utilizadas nos parâmetros do número de ovos e número de postura variou de 4 a 11 (gaiolas de oviposição), sendo as gaiolas oviposição formadas de acordo com a quantidade de casais de mesmo dia que emergiam de cada tratamento.

Todos os dados foram submetidos ao teste de homocedasticidade (Levene $P<0,05$ ) e normalidade (Cramer Von Misses $P<0,05$ ), quando não atenderam essas pressuposições foram transformados de acordo com o teste de Box-Cox e os dados submetidos ao teste $\mathrm{F}(P<0,05)$ e quando significativo, as médias foram comparadas pelo teste Tukey $(P<0,05)$. Os dados que mesmo após a transformação não apresentaram homogeneidade das variâncias ou distribuição normal, foram submetidos ao teste de KruskalWallis $(P<0,05)$ pelo software SAS 9.3 (SAS INSTITUTE, 2011) e quando significativo, as médias foram comparadas pelo teste de Dunns $(P<0,05)$ através do software Prism 4 (GRAPHPAD, 2003).

Realizou-se ainda duas análises multivariadas, a análise de agrupamento hierárquica (AAH), utilizando o método de Ward e a distância euclidiana como medida de dissimilaridade e a análise de componentes 


\section{(0) \\ Revista Agrarian \\ ISSN: 1984-2538}

principais (ACP), com estas análises foi possível classificar os cultivares com maior ou menor similaridade em níveis de resistência, sendo estas análises realizadas pelo software Statistica versão 7.0 (Statsoft, 2004).

\section{Resultados e Discussão}

No teste de não preferência alimentar com chance de escolha (Tabela 1), não foram observadas diferenças estatísticas entre os cultivares de milho em relação a atratividade e a porcentagem de injúria. A não ocorrência de diferenças entre os cultivares de milho neste teste, pode ter ocorrido devido as lagartas serem territorialistas, impedindo que houvesse um acumulo de lagartas em um disco foliar, o que aumentaria o consumo nesse determinado cultivar.

Tabela 1. Número médio ( $\pm \mathrm{EP})$ de lagartas de Spodoptera frugiperda de $3^{\circ}$ instar atraídas e porcentagem de injúria em discos foliares de cultivares de milho, em teste com e sem chance de escolha. Jaboticabal, SP, 2013/14.

\begin{tabular}{|c|c|c|c|c|c|c|}
\hline \multirow{3}{*}{ Cultivares (C) } & \multicolumn{3}{|c|}{ Teste com chance de escolha } & \multicolumn{3}{|c|}{ Teste sem chance de escolha } \\
\hline & \multicolumn{2}{|c|}{ Número de lagartas atraídas } & \multirow{2}{*}{ Injúria (\%) } & \multicolumn{2}{|c|}{ Número de lagartas atraídas } & \multirow{2}{*}{ Injúria (\%) } \\
\hline & 1 a $30 \mathrm{~min}$ & $1 \mathrm{a} 12 \mathrm{~h}$ & & 1 a $30 \mathrm{~min}$ & $1 \mathrm{a} 12 \mathrm{~h}$ & \\
\hline AG 7088 & $0,5 \pm 0,22$ & $0,4 \pm 0,16$ & $9,6 \pm 5,28$ & $0,7 \pm 0,11 \mathrm{~b}$ & $0,9 \pm 0,03$ & $78,9 \pm 10,31 \mathrm{ab}$ \\
\hline BX 1293 & $0,3 \pm 0,11$ & $0,7 \pm 0,20$ & $6,0 \pm 2,26$ & $0,5 \pm 0,15 a b$ & $0,8 \pm 0,08$ & $67,1 \pm 12,18 \mathrm{ab}$ \\
\hline AG 5055 & $0,2 \pm 0,09$ & $0,3 \pm 0,13$ & $4,3 \pm 2,77$ & $0,3 \pm 0,10 \mathrm{ab}$ & $0,7 \pm 0,13$ & $54,0 \pm 14,43 a b$ \\
\hline IAC 8390 & $0,6 \pm 0,11$ & $0,9 \pm 0,24$ & $23,0 \pm 8,74$ & $0,4 \pm 0,19 \mathrm{ab}$ & $0,6 \pm 0,12$ & $56,8 \pm 11,98 \mathrm{ab}$ \\
\hline AS 1581 & $0,2 \pm 0,14$ & $0,5 \pm 0,12$ & $5,8 \pm 1,98$ & $0,2 \pm 0,11 \mathrm{ab}$ & $0,7 \pm 0,10$ & $46,2 \pm 11,77 \mathrm{a}$ \\
\hline TRUCK & $0,6 \pm 0,22$ & $0,9 \pm 0,19$ & $12,0 \pm 3,47$ & $0,4 \pm 0,13 \mathrm{ab}$ & $0,8 \pm 0,09$ & $53,6 \pm 9,79 a b$ \\
\hline AS 1596 & $0,4 \pm 0,18$ & $0,6 \pm 0,25$ & $16,7 \pm 9,35$ & $0,0 \pm 0,00 \mathrm{a}$ & $0,6 \pm 0,08$ & $55,3 \pm 11,39 a b$ \\
\hline SHS 7780 & $0,2 \pm 0,11$ & $0,5 \pm 0,18$ & $5,4 \pm 2,86$ & $0,5 \pm 0,11 \mathrm{ab}$ & $0,9 \pm 0,03$ & $93,4 \pm 1,37 b$ \\
\hline DKB 370 & $0,6 \pm 0,16$ & $0,7 \pm 0,19$ & $15,2 \pm 6,55$ & $0,5 \pm 0,13 \mathrm{ab}$ & $0,8 \pm 0,04$ & $81,1 \pm 7,78 \mathrm{ab}$ \\
\hline $20 \mathrm{~A} 78$ & $0,2 \pm 0,10$ & $0,4 \pm 0,12$ & $4,5 \pm 1,70$ & $0,5 \pm 0,14 \mathrm{ab}$ & $0,7 \pm 0,07$ & $80,9 \pm 7,17 \mathrm{ab}$ \\
\hline 2B587 & $0,5 \pm 0,18$ & $0,4 \pm 0,26$ & $8,1 \pm 5,84$ & $0,5 \pm 0,15 \mathrm{ab}$ & $0,7 \pm 0,11$ & $73,4 \pm 12,16 a b$ \\
\hline$H(\mathrm{C})$ & $15,20^{\mathrm{ns}}$ & $13,92^{\text {ns }}$ & $8,93^{\mathrm{ns}}$ & $23,97 * *$ & $15,50^{\mathrm{ns}}$ & $26,80 * *$ \\
\hline$P$ (Valor) & 0,125 & 0,1765 & 0,5389 & 0,0077 & 0,1148 & 0,0028 \\
\hline GL (Residuo) & 99 & 99 & 99 & 99 & 99 & 99 \\
\hline
\end{tabular}

Médias seguidas de diferentes letras na coluna diferem significativamente entre si pelo teste de Tukey $(P<0,05)$. **Significativo a pelo teste $\mathrm{F}$ a $1 \%$ de probabilidade, ${ }^{\text {ns }}$ Não significativo pelo teste $\mathrm{F}$ a $5 \%$ de probabilidade.

Segundo Luginbill (1928) é comum encontrar apenas uma lagarta desenvolvida por cartucho devido ao hábito canibal desta espécie apresenta a partir do terceiro instar. Entretanto, podem ser encontradas larvas de diferentes instares dentro de um mesmo cartucho.

Já para o teste sem chance de escolha, que é o teste que mais se assemelha as condições de campo, os cultivares diferiram entre si na atratividade no período de 1 a 30 minutos, onde AS 1596 foi menos preferido, diferindo significativamente de AG 7088. Entretanto, no período de 1 a 12 horas após o início do teste, os cultivares de milho não diferiram entre si. No que se diz respeito a porcentagem de injúria, o cultivar
AS 1581 foi significativamente menos preferido de SHS 7780 (Tabela 1).

Os cultivares AS 1596 e AS 1581 devem apresentar em suas constituições genotípicas, mecanismos que interferiram no comportamento das lagartas, proporcionando a resistência na categoria não preferência. Segundo Smith (2005) e Boiça Júnior et al, (2014), as plantas possuem mecanismos de defesa contra o ataque de insetos, que desenvolveram no decorrer da evolução, de modo que, estes podem ser de ordem morfológica, física ou química. Estes autores relatam ainda que, estes mecanismos podem ocorrer individualmente ou de forma associada. 


\section{Revista Agrarian}

ISSN: 1984-2538

A menor alimentação das lagartas no cultivar AS 1581 pode ser uma consequência de características de resistência, corroborando com Boiça Júnior et al. (2014), que relatam que genótipos menos consumidos possivelmente tenham maior presença de deterrentes e/ou menor teor de estimulantes, ou ainda que características morfológicas, como a dimensão e à disposição das estruturas vegetais e aos fatores da epiderme, que se refere à espessura, a dureza, a textura, a cerosidade e a pilosidade da planta.

No teste de antibiose, pode-se verificar que houve influência das diferentes cultivares de milho sobre o desenvolvimento de S. frugiperda apenas para o peso larval, de modo que, lagartas alimentadas nos cultivares AG 7088, BX 1293, AG 5055 e IAC 8390 apresentaram peso larval significativamente menor que dos demais cultivares (Tabela 2).

Tabela 2. Média ( \pm EP) do peso de larvas e pupas $(\mathrm{mg})$, período larval, pupal e longevidade de adultos (dias), razão sexual e ciclo total de Spodoptera frugiperda criada em cultivares de milho convencional. Jaboticabal, SP, 2013/14.

\begin{tabular}{ccccc}
\hline Cultivar $(\mathrm{C})$ & Peso larval & Peso pupal & Período larval & Período pupal \\
\hline AG 7088 & $308,2 \pm 26,76 \mathrm{a}$ & $201,4 \pm 7,89$ & $15,5 \pm 0,61$ & $8,9 \pm 0,16$ \\
BX 1293 & $289,0 \pm 68,67 \mathrm{a}$ & $213,2 \pm 18,18$ & $14,8 \pm 0,54$ & $9,1 \pm 0,23$ \\
AG 5055 & $324,3 \pm 103,91 \mathrm{a}$ & $211,0 \pm 27,38$ & $14,7 \pm 0,51$ & $9,0 \pm 0,19$ \\
IAC 8390 & $319,6 \pm 56,80 \mathrm{a}$ & $210,2 \pm 12,61$ & $15,1 \pm 0,70$ & $9,0 \pm 0,11$ \\
AS 1581 & $398,7 \pm 26,40 \mathrm{~b}$ & $224,4 \pm 19,96$ & $14,0 \pm 0,23$ & $9,0 \pm 0,20$ \\
TRUCK & $376,7 \pm 43,58 \mathrm{~b}$ & $221,2 \pm 6,84$ & $14,1 \pm 0,35$ & $8,9 \pm 0,13$ \\
AS 1596 & $432,7 \pm 42,43 \mathrm{~b}$ & $206,7 \pm 21,73$ & $13,8 \pm 0,22$ & $8,9 \pm 0,13$ \\
SHS 7780 & $404,4 \pm 30,76 \mathrm{~b}$ & $205,9 \pm 13,01$ & $14,0 \pm 0,25$ & $8,5 \pm 0,40$ \\
DKB 370 & $422,0 \pm 47,32 \mathrm{~b}$ & $212,9 \pm 6,29$ & $13,8 \pm 0,18$ & $8,4 \pm 0,37$ \\
20A78 & $391,3 \pm 56,30 \mathrm{~b}$ & $216,5 \pm 12,51$ & $14,0 \pm 0,19$ & $8,6 \pm 0,17$ \\
2B587 & $472,7 \pm 44,89 \mathrm{~b}$ & $220,6 \pm 18,80$ & $13,6 \pm 0,11$ & $8,4 \pm 0,23$ \\
\hline$F($ C) & $6,30 * *$ & $0,94^{\mathrm{ns}}$ & & - \\
$H$ (C) & - & - & $13,44^{\mathrm{ns}}$ & $11,31^{\mathrm{ns}}$ \\
$P$ (Valor) & $<0,0001$ & 0,504 & 0,2003 & 0,3336 \\
GL (Residuo) & 44 & 44 & 44 & 44 \\
\hline
\end{tabular}

Médias seguidas de diferentes letras na coluna diferem significativamente entre si pelo teste de Tukey

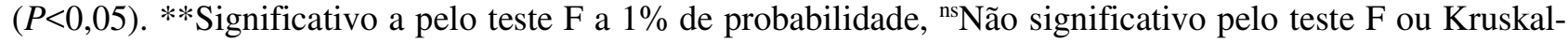
Wallis a $5 \%$ de probabilidade.

O peso larval é um importante parâmetro biológico do inseto que deve ser observado em teste de resistência de plantas, pois um inseto que apresente menor peso em relação a outro, poderá apresentar limitações durante o restante de seu ciclo biológico. Silveira et al. (1997), em um estudo sobre os efeitos de 11 genótipos de milho nos aspectos biológicos de $S$. frugiperda, também verificaram reduzido peso larval quando as lagartas foram alimentadas no genótipo Zapalote Chico.
Apesar das cultivares AG 7088, BX 1293, AG 5055 e IAC 8390 terem proporcionado menor peso larval, observando-se também efeito negativo nos demais parâmetros biológicos, assim pode-se inferir que o menor peso das lagartas não influenciou negativamente a biologia da praga.

Em relação a razão sexual, longevidade e ciclo de vida, não foram observadas diferenças significativas entre os cultivares de milho submetidos ao teste de antibiose (Tabela 3). 


\section{(-) \\ Revista Agrarian \\ ISSN: $1984-2538$}

Tabela 3. Média ( $\pm \mathrm{EP})$ do peso de larvas e pupas $(\mathrm{mg})$, período larval, pupal e longevidade de adultos (dias), razão sexual e ciclo total de Spodoptera frugiperda criada em cultivares de milho convencional. Jaboticabal, SP, 2013/14.

\begin{tabular}{cccc}
\hline Cultivar $($ C) & Razão sexual & Longevidade & Ciclo de vida \\
\hline AG 7088 & $0,5 \pm 0,43$ & $8,5 \pm 0,37$ & $33,1 \pm 1,05$ \\
BX 1293 & $0,5 \pm 0,09$ & $8,5 \pm 0,85$ & $32,2 \pm 1,35$ \\
AG 5055 & $0,3 \pm 0,45$ & $7,9 \pm 0,33$ & $31,4 \pm 0,59$ \\
IAC 8390 & $0,3 \pm 0,08$ & $8,9 \pm 0,48$ & $32,0 \pm 0,83$ \\
AS 1581 & $0,5 \pm 0,13$ & $8,1 \pm 0,49$ & $31,1 \pm 0,77$ \\
TRUCK & $0,4 \pm 0,08$ & $7,5 \pm 0,35$ & $30,1 \pm 0,79$ \\
AS 1596 & $0,4 \pm 0,07$ & $8,4 \pm 0,18$ & $31,0 \pm 0,23$ \\
SHS 7780 & $0,5 \pm 0,10$ & $9,5 \pm 0,43$ & $31,9 \pm 0,87$ \\
DKB 370 & $0,6 \pm 0,05$ & $10,1 \pm 0,5$ & $32,6 \pm 0,61$ \\
20A78 & $0,5 \pm 0,11$ & $8,6 \pm 1,01$ & $31,1 \pm 0,60$ \\
2B587 & $0,5 \pm 0,06$ & $8,8 \pm 0,35$ & $31,0 \pm 0,19$ \\
\hline$F$ (C) & $1,23^{\text {ns }}$ & $1,88^{\text {ns }}$ & $1,17^{\text {ns }}$ \\
H (C) & - & - & - \\
$P$ (Valor) & 0,3011 & 0,0749 & 0,3378 \\
GL (Resíduo) & 44 & 44 & 44 \\
\hline
\end{tabular}

Médias seguidas de diferentes letras na coluna diferem significativamente entre si pelo teste de Tukey $(P<0,05)$. ${ }^{* *}$ Significativo a pelo teste $\mathrm{F}$ a $1 \%$ de probabilidade, ${ }^{\text {ns }}$ Não significativo pelo teste $\mathrm{F}$ ou KruskalWallis a $5 \%$ de probabilidade.

Com relação à viabilidade larval, viabilidade pupal, e viabilidade total não foram

observadas diferenças significativas entre os genótipos nestes parâmetros (Tabela 4).

Tabela 4. Média ( \pm EP) da viabilidade larval, pupal e total $(\%)$, número de ovos e número de posturas de Spodoptera frugiperda criadas em cultivares de milho convencional. Jaboticabal, SP, 2013/14.

\begin{tabular}{ccccrr}
\hline Cultivar (C) & Viabilidade larval & Viabilidade pupal & Viabilidade total & Número de ovos & \multicolumn{1}{c}{$\begin{array}{c}\text { Número de } \\
\text { postura }\end{array}$} \\
\hline AG 7088 & $90,0 \pm 6,67$ & $93,3 \pm 4,08$ & $83,3 \pm 5,26$ & $867,5 \pm 171,51 \mathrm{~b}$ & $6,1 \pm 0,91 \mathrm{a}$ \\
BX 1293 & $80,0 \pm 6,23$ & $80,7 \pm 10,97$ & $60,0 \pm 8,50$ & $897,8 \pm 256,77 \mathrm{~b}$ & $9,0 \pm 3,67 \mathrm{a}$ \\
AG 5055 & $86,7 \pm 3,33$ & $88,7 \pm 4,37$ & $80,0 \pm 6,23$ & $1060,0 \pm 210,03 \mathrm{~b}$ & $17,4 \pm 4,36 \mathrm{~b}$ \\
IAC 8390 & $93,3 \pm 4,01$ & $84,6 \pm 7,42$ & $80,0 \pm 9,72$ & $398,0 \pm 221,73 \mathrm{a}$ & $5,0 \pm 1,78 \mathrm{a}$ \\
AS 1581 & $83,3 \pm 7,5$ & $84,3 \pm 4,20$ & $70,0 \pm 6,24$ & $885,4 \pm 177,56 \mathrm{~b}$ & $15,8 \pm 2,36 \mathrm{~b}$ \\
TRUCK & $100 \pm 0,00$ & $80,0 \pm 6,24$ & $80,0 \pm 6,24$ & $647,7 \pm 172,42 \mathrm{a}$ & $7,5 \pm 1,90 \mathrm{a}$ \\
AS 1596 & $86,7 \pm 9,72$ & $80,0 \pm 13,3$ & $66,6 \pm 11,79$ & $860,6 \pm 117,86 \mathrm{~b}$ & $10,3 \pm 1,22 \mathrm{~b}$ \\
SHS 7780 & $93,3 \pm 4,09$ & $78,0 \pm 6,96$ & $73,3 \pm 8,50$ & $913,6 \pm 143,41 \mathrm{~b}$ & $10,9 \pm 2,58 \mathrm{a}$ \\
DKB 370 & $93,3 \pm 4,08$ & $89,3 \pm 4,40$ & $83,3 \pm 5,24$ & $1778,0 \pm 346,10 \mathrm{~b}$ & $17,5 \pm 3,92 \mathrm{~b}$ \\
20A78 & $96,7 \pm 3,33$ & $79,3 \pm 6,18$ & $76,7 \pm 6,67$ & $970,7 \pm 195,00 \mathrm{~b}$ & $10,2 \pm 2,44 \mathrm{a}$ \\
2B587 & $100,0 \pm 0,00$ & $93,3 \pm 6,67$ & $90,0 \pm 6,67$ & $1253,3 \pm 161,24 \mathrm{~b}$ & $13,8 \pm 1,94 \mathrm{~b}$ \\
\hline$F(C)$ & - & - & - & $2,42 *$ & $2,54 *$ \\
$H$ (C) & $14,64^{\mathrm{ns}}$ & $7,34^{\mathrm{ns}}$ & $10,74^{\mathrm{ns}}$ & - & - \\
$P$ (Valor) & 0,1455 & 0,8142 & 0,3779 & 0,0141 & 0,0102 \\
GL (Resíduo) & 44 & 44 & 44 & 81 & 81 \\
\hline
\end{tabular}

Médias seguidas de diferentes letras na coluna diferem significativamente entre si pelo teste de Tukey $(P<0,05)$. *Significativo a pelo teste $\mathrm{F}$ a $5 \%$ de probabilidade, ${ }^{\text {ns }}$ Não significativo pelo teste Kruskal-Wallis a $5 \%$ de probabilidade. 


\section{Revista Agrarian}

ISSN: 1984-2538

Segundo Ramalho et al. (2012), para que um substrato alimentar seja considerado ideal ao desenvolvimento de insetos, este deve proporcionar altas viabilidades tanto de larvas quanto de pupas.

No que se diz respeito ao número de ovos e número de posturas, foram observadas diferenças entre os cultivares de milho, onde os adultos oriundos de lagartas alimentadas nos cultivares IAC 8390 e TRUCK, apresentaram menor capacidade reprodutiva, em decorrência do número de ovos significativamente menor, quando comparado aos demais cultivares (Tabela 4).

Esse menor número de ovos caracteriza uma resistência na categoria antibiose, uma vez que, os insetos alimentaram-se normalmente dos cultivares de milho, e estes causaram um efeito adverso nos aspectos biológicos dos insetos, que foi a redução no número de ovos. Esse resultado corrobora com Boiça Júnior et al. (2014), que descrevem que os efeitos adversos de plantas resistentes a insetos sobre a biologia dos insetos, e alterações na fecundidade de adultos. Ainda segundo Cruz (1995), a fertilidade dos adultos de S. frugiperda é relacionada com a qualidade do alimente utilizado na fase larval, ou seja, um alimento de melhor qualidade e quantidade deve proporcionar insetos de melhor fertilidade.

Para a determinação de genótipos resistentes a insetos, foi realizada uma análise multivariada dos dados, segundo Costa et al. (2013), essa análise é uma importante ferramenta que facilita na discriminação dos genótipos testados, e por meio da análise de agrupamento hierárquica, observou-se a distinção entre as cultivares de milho, em quatro distintos grupos, sendo a separação dos grupos realizada entre as distâncias euclidianas de 5,35.

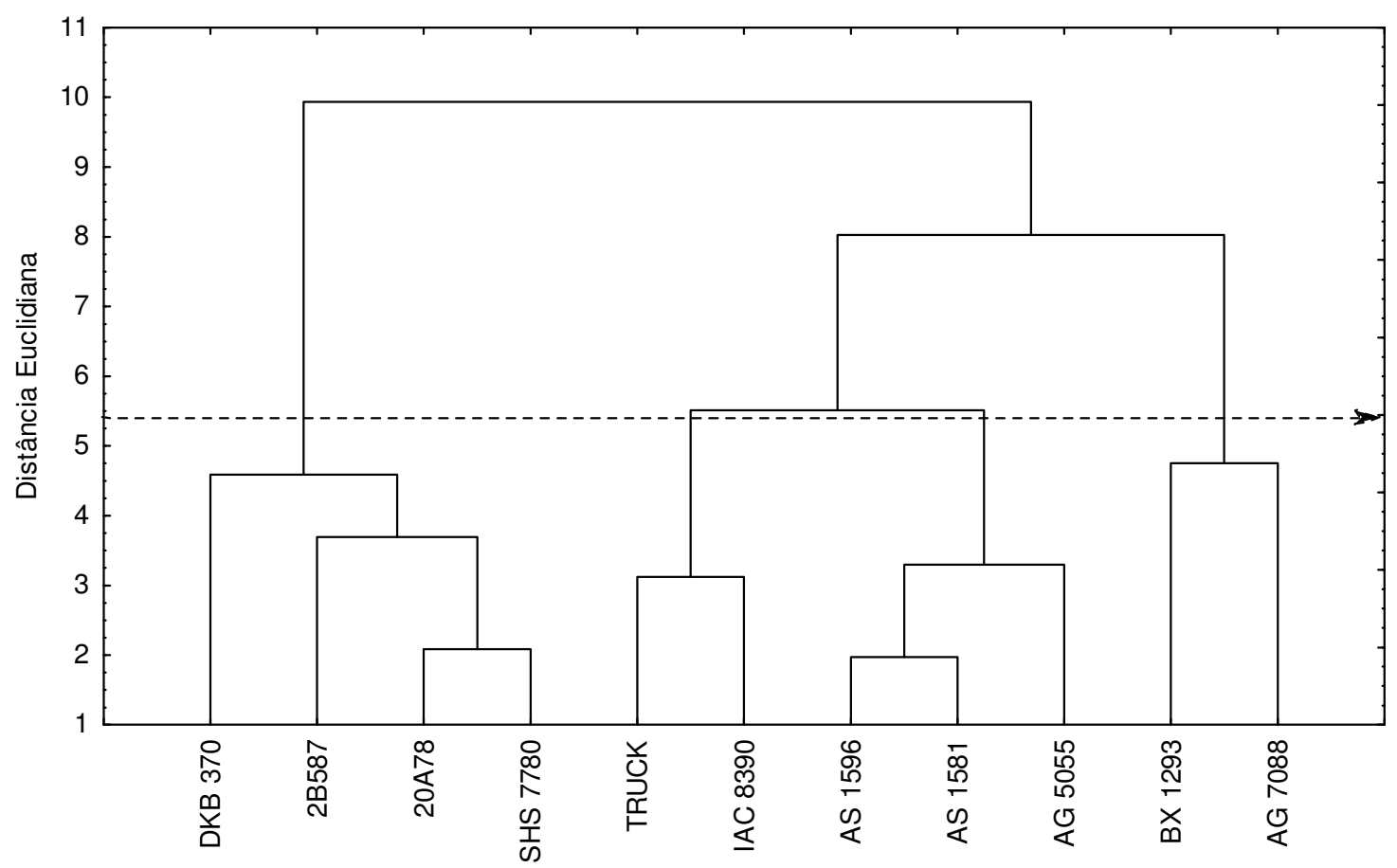

Figura 1. Dendrograma baseado nos parâmetros biológicos de Spodoptera frugiperda alimentadas com cultivares de milho. O método de agrupamento utilizado foi o de Ward com a distância euclidiana como medida de dissimilaridade. A seta indica a distância euclidiana utilizada para a separação dos grupos.

Os cultivares BX 1293 e AG 7088 foram agrupados formando o grupo um. Já os cultivares AS 1596, AS 1581 e AG 5055 formaram o segundo grupo, por apresentarem menor dissimilaridade entre si. Os genótipos TRUCK e IAC 8390 foram agrupados ao centro da figura, formando o terceiro grupo. E por fim o quarto 


\section{(ㅇ. \\ Revista Agrarian \\ ISSN: 1984-2538}

grupo foi formado pelos genótipos DKB 370, 2B587, 20 A78 e SHS7780 (Figura 1).

A partir desta análise, pode-se observar que os genótipos apresentam diferentes níveis de resistência, uma vez que, moderada resistência foi observada para os genótipos presentes no terceiro grupo (TRUCK e IAC 8390), que apresentaram menor capacidade reprodutiva dos adultos. Já os genótipos do grupo um e dois (grupo 1 - BX 1293 e AG 7088, grupo 2 - AS 1596, AS 1581 e AG 5055) são classificados como suscetíveis, pois afetaram pouco o desenvolvimento biológico e a alimentação dos insetos. E os genótipos do grupo quatro (DKB 370, 2B587, 20A78 e SHS7780) são classificados como altamente suscetíveis por proporcionar bom desenvolvimento da praga.

$\mathrm{Na}$ análise de componentes principais (Figura 2), os cultivares AG 7088 e BX 1293 se agruparam na direita no quarto quadrante, sendo influenciados principalmente pelo período larval e ciclo total. Já os cultivares IAC 8390, AG 5055, AS 1581, AS 1596 e TRUCK se agruparam a direita no primeiro quadrante, e foram influenciados principalmente pelo período pupal, e negativamente pelo número total de ovos, razão sexual e longevidade de adultos. Os cultivares DKB 370 e SHS 7780 foram agrupados a esquerda no terceiro quadrante, sendo que estes cultivares foram mais influenciados pelo total de posturas, total de ovos, razão sexual e longevidade de adultos. Em relação aos cultivares 2B587 e 20A78, estes foram positivamente influenciados pelo peso pupal, peso larval, viabilidade total e pupal (Figura 2).

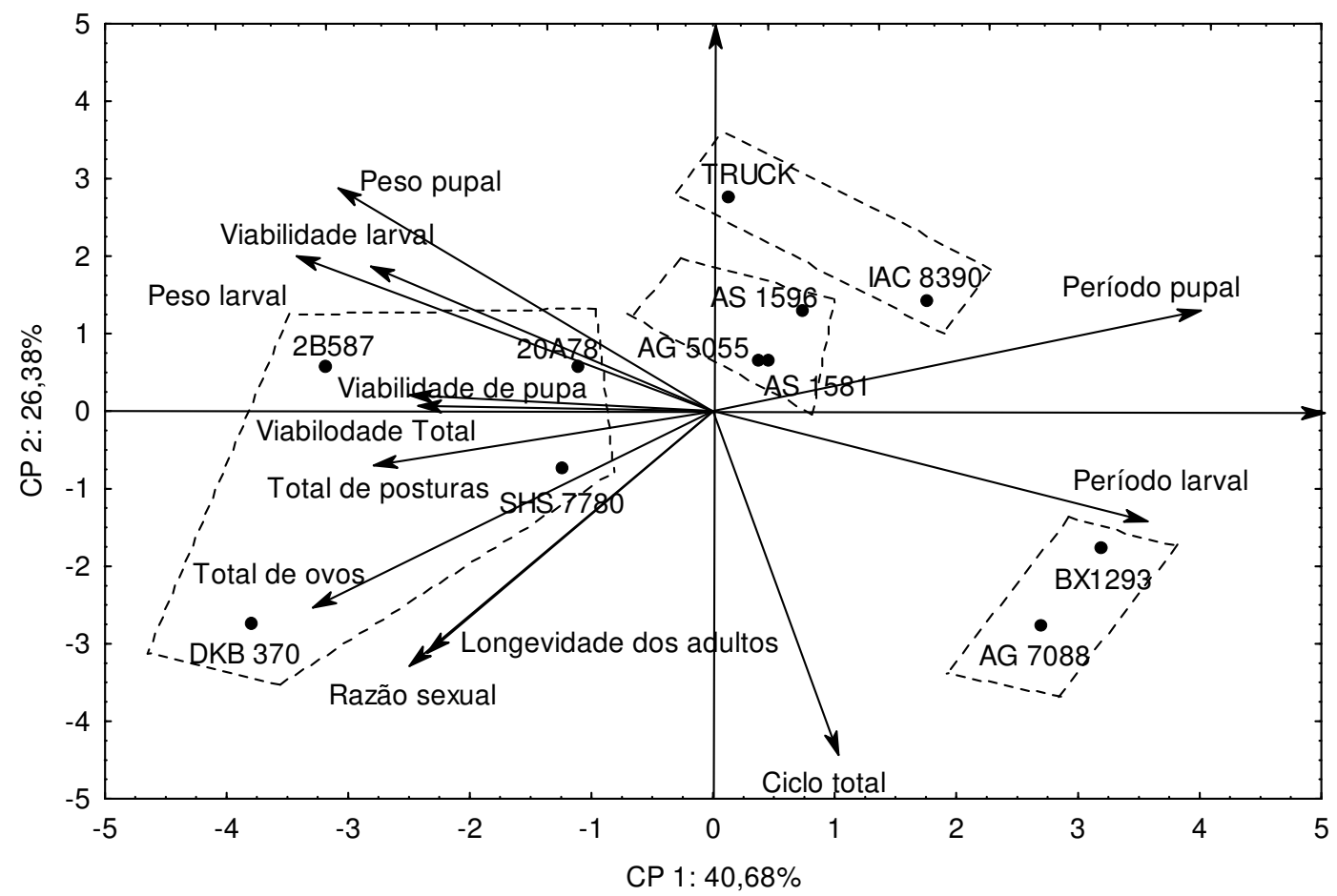

Figura 2. Distribuição dos parâmetros biológicos de Spodoptera frugiperda alimentadas em cultivares de milho, de acordo com a análise dos componentes principais.

De modo geral, verificou-se que alguns cultivares de milho testados, apresentam características de resistência tanto na categoria não preferência para alimentação quanto antibiose. Em relação à análise multivariada, o método de agrupamento utilizando a distância euclidiana como medida de dissimilaridade entre os cultivares, favorece o entendimento dos níveis de resistência, e a análise de componentes principais permite a visualização do efeito do substrato alimentar (cultivar), sobre cada parâmetro biológico do inseto, e o dimensionar a 


\section{(-) \\ Revista Agrarian \\ ISSN: 1984-2538}

intensidade desse efeito. Os resultados encontrados neste trabalho são promissores, indicando quais cultivares apresentam características de resistência a $S$. frugiperda. Podendo estes cultivares serem utilizadas no manejo integrado de pragas, associadas a outras táticas de controle ou em programas de melhoramento genético que visem a obtenção de novas cultivares resistentes a esta praga, como ressaltado por Cunha et al. (2008). Estudos futuros são necessários para verificar as possíveis causas da resistência dessas cultivares a $S$. frugiperda, buscando elucidar cada vez mais essa complexa interação hospedeiro-praga, facilitando assim a utilização dessas cultivares em programas de melhoramento genético.

\section{Conclusões}

A cultivar AS 1581 apresentou características de resistência na categoria não preferência para alimentação, as cultivares TRUCK e IAC 8390, apresentaram características de resistência na categoria antibiose a $S$. frugiperda.

\section{Referências}

BESERRA, E.B.; PARRA, J.R.P. Impact of the number of Spodoptera frugiperda egg layers on parasitism by Trichogramma atopovirilia. Scientia Agrícola, v.62, n.2, p.190-193, 2005.

BOIÇA JÚNIOR, A.L.; MARTINELLI, S.; PEREIRA, M.F.A. Resistência de genótipos de milho ao ataque de Spodoptera frugiperda (J.E. Smith, 1797) e Helicoverpa zea (Boddie 1850), (Lepidoptera: Noctuidae). Revista Ecossistema, v.26. n.1. p.86-90, 2001.

BOIÇA JÚNIOR, A.L.; SOUZA, B.H.S.; COSTA, E.N.; MORAES, R.F.O.; EDUARDO W.I.; RIBEIRO, Z.A. Resistência de plantas e produtos naturais e as implicações na interação inseto-planta. In: BUSOLI, A.C.; SOUZA, L.A.; ALENCAR, J.R.C.C.; FRAGA, D.F.; GRIGOLLI, J.F.J. Tópicos em entomologia Agrícola - IV. Jaboticabal: Gráfica e editora Multipress. p. 291-308. 2014.

CAMPOS, A.P.; BOIÇA JÚNIOR, A.L. Lagartas de Spodoptera frugiperda (J.E. SMITH) (Lepidoptera: Noctuidae) submetidas a diferentes concentrações de óleo de nim. Revista Brasileira de Milho e Sorgo, v.11, n.2, p.137-144, 2012.
CÉLERES. $3^{\circ}$ levantamento de adoção da biotecnologia agrícola no Brasil, safra 2016/17. Informativo Biotecnologia. Disponível em:< http://www.celeres.com.br/3o-levantamento-deadocao-da-biotecnologia-agricola-no-brasil-safra201617/\#>. Acesso em 08 de maio de 2017.

CONAB - COMPANHIA NACIONAL DE ABASTECIMENTO. Acompanhamento de safra brasileira: grãos, v. 4 - Safra 2016/17, n. 7 - Sétimo Levantamento, / Companhia Nacional de Abastecimento - Brasília, 2017. 162p.

CORREIA, A.A.; TEIXEIRA, V.W.; TEIXEIRA, A.A.C.; OLIVEIRA, J.V. de; TORRES, J.B. Morfologia do canal alimentar de lagartas de Spodoptera frugiperda (J. E. Smith) (Lepidoptera: Noctuidae) alimentadas com folhas tratadas com nim. Neotropical Entomology, v.38, n.1, p.8391, 2009.

COSTA, E.N.; SOUZA, B.H.S.; BOTTEGA, D.B.; OLIVEIRA, F.Q.O.; RIBEIRO, Z.A.; BOIÇA JÚNIOR, A.L. Divergência genética de genótipos de feijoeiro a infestação de Zabrotes subfasciatus (Bohemann) (Coleoptera: Bruchidae) Semina: Ciências Agrárias, v.34, n.6, p.27372752, 2013.

CRUZ, I.; FIGUEIREDO, M.deL.C.; SILVA, R.B. Controle Biológico de Pragas de Milho. Ciência e Ambiente, v.43, n.1. p.165-190. 2011.

CUNHA, U.S.; MARTINS, J. F. S.; PORTO, M. P.; GARCIA, M. S.; BERNARDI, O.; TRECHA, C. O.; BERNARDI, D.; JARDIM, E. O.; BACK, E. C. U. Resistência de genótipos de milho para cultivo em várzeas subtropicais à lagarta-docartucho $S$ podoptera frugiperda. Ciência Rural, Santa Maria, v. 38, n. 4, p. 1125-1128, 2008.

FARIAS, J. R.; ANDOW, D. A.; HORIKOSHI, R. J.; SORGATTO, R. J.; FRESIA, P.; SANTOS, A. C. dos; OMOTO, C. Field-evolved resistance to Cry1F maize by Spodoptera frugiperda (Lepidoptera: Noctuidae) in Brazil. Crop Protection, Guildford, v. 64, v. 4, p. 150-158, 2014.

GRAPHPAD. GraphPad Prism Version 4.00. EUA, San Diego. 2003.

GREENE, G. L.; LEPLA, N. C.; DICKERSON, W. A. Velvetbean caterpillar: a rearing procedure and artificial medium. Journal of Economic Entomology, College Park, v. 69, n. 4, p. 488497, 1976. 


\section{(ㅇ. \\ Revista Agrarian \\ ISSN: 1984-2538}

LIMA, F.W.N.; OHASHI, O.S.; SOUZA, F.R.S.; GOMES, F.S. Avaliação de acessos de milho para resistência a Spodoptera frugiperda (Smith) (Lepidoptera: Noctuidae) em laboratório. Acta Amazônica, v.36, n.2, p.147-150, 2006.

LUGINBILL, P. The fall armyworm. Technical Bulletin, Washington, v. 34. n. 1, p. 73, 1928.

MORAES, A.R.A.; LOURENÇÃO, A.L.; PATERNIANI, M.E.A.G.Z. Resistência de híbridos de milho convencionais e isogênicos transgênicos a Spodoptera frugiperda (Lepidoptera: Noctuidae). Bragantia, v.74, n. 1, p.50-57, 2015.

NOGUEIRA, L. Categorias e níveis de resistência de genótipos de milho crioulo a Spodoptera frugiperda (J. E. Smith, 1797) (Lepidóptera: Noctuidae). 2015. $101 \mathrm{f}$. Dissertação (Mestrado em Entomologia) Universidade Estadual Paulista, Faculdade de Ciências Agrárias e Veterinárias, Jaboticabal, 2015.

OTA, E.C.; LOURENÇÃO, A.L.; DUARTE, A.P.; RAMOS JUNIOR, E.U.; ITO, M.A. Desempenho de cultivares de milho em relação à lagarta-do-cartucho. Bragantia, v.70, n.4, p.1-10, 2011.

RAMALHO, D.G.; VIEL, S.R.; VACARI, A.M.; DE BORTOLI S.A.; LOPES M.M.; LAURENTIS, V.L.; VEIGA, A.C.P. Criteria for optimization of mass rearing of the parasitoid Cotesia flavipes in the laboratory. Journal of Research in Biology, v.2, n.5, p.529-536, 2012.

SILVEIRA， L.C.P.; VENDRAMIM， J.D.; ROSSETTO, C.J. Efeito de Genótipos de Milho no Desenvolvimento de Spodoptera frugiperda (J.E. Smith). Anais da Sociedade Entomológica Brasileira, v.26, n.2, p.291-298, 1997.

SMITH, C.M. Plant resistence to arthropods: molecular and conventional approaches. Berlin: Springer. 2005. 423p.

SORGATTO, R.J.; BERNARDI, O.; OMOTO, C. Survival and Development of Spodoptera frugiperda and Chrysodeixis includens (Lepidoptera: Noctuidae) on Bt Cotton and Implications for Resistance Management Strategies in Brazil. Environmental Entomology, v.44, n.1, p.186-192, 2015.
SAS INSTITUTE. Sas/Stat User Software: Changes and 14 Enhancements through Release. Estados Unidos, Cary. Version 9.3. 2011.

STATSOFT, Inc. 2004. STATISTICA (data analyses software system), version 7. Disponível em: <71el.statsoft.com>.

VIANA, P.A.; PONTEZA, M.R. Avaliação de antibiose e não-preferência em cultivares de milho selecionados com resistência à lagarta-docartucho. Bragantia, v.59, n.1, p.27-33, 2000.

WAQUIL, J.M.; VILLELA, F.M.F.; FOSTER, J.E. Resistência do milho (Zea mays L.) transgênico (Bt) à lagarta-do-cartucho, Spodoptera frugiperda (Smith) (Lepidoptera: Noctuidae). Revista Brasileira de Milho e Sorgo, v.1, n.3, p.1-11, 2002.

ZANCANARO, P.O.; BUCHWEITZ, E.D.; BOIÇA JUNIOR, A.L.; MORO, J.R. Avaliação de tecnologias de refúgio no cultivo de milho transgênico. Pesquisa Agropecuária Brasileira, v.47, n.7, p. 886-891, 2012. 